\title{
Metabolic control and school performance in children with type 1 diabetes
}

\section{Control metabólico y rendimiento escolar en niños con diabetes tipo 1}

\author{
Rossana Román ${ }^{\mathrm{a}, \mathrm{b}}$, Víctor Garrido ${ }^{\mathrm{a}, \mathrm{e}}$, Valentina Novoa ${ }^{\mathrm{a}, \mathrm{e}}$, Gabriela Mundaca $^{\mathrm{a}, \mathrm{e}}$, Ema Pichuante ${ }^{\mathrm{a}, \mathrm{e}}$, \\ Álvaro Rivera ${ }^{\mathrm{a}, \mathrm{e}}$, Alberto Torres ${ }^{\mathrm{a}, \mathrm{d}}$, Margarita Fuentes $^{\mathrm{a}, \mathrm{c}}$, Alison Fuentes ${ }^{\mathrm{a}, \mathrm{e}}$, Jeannette Linares ${ }^{\mathrm{a}, \mathrm{b}}$
}

\author{
aFaculty of Medicine and Dentistry, University of Antofagasta \\ bDepartment of Pediatrics, Dr. Leonardo Guzmán Hospital of Antofagasta \\ 'Dental Surgeon, Biostatistics and Epidemiology specialist, Master in Public Health \\ dSociologist \\ eMedical students, Antofagasta, Chile
}

Recibido: 14-08-2016; Aceptado: 10-04-2017

\begin{abstract}
The impact of type 1 diabetes (T1D) on school performance is controversial. Objective: To study the relationship between school performance and metabolic control in children with T1D (Ch-T1D), comparing their school grades to general population children (Ch-GP). Patients and Method: Clinical data for $66 \mathrm{Ch}-\mathrm{T} 1 \mathrm{D}$ was reviewed, school grades were compared in Ch-T1D with Glycated Haemoglobin (HbAlc) HbAlc $<7.5 \%$ and $\geq 7.5 \%$. School marks were also compared between Ch-T1D and Ch-GP from the same level, community and school type (public, private o chartered). Simple linear regression analysis and Mann Whitney test were used to compare groups. A p $<0.05$ was considered significant. Results: Ch-T1D were: $13.4 \pm 2.9$ years old, T1D duration: $5.3 \pm 3.2$ years, HbA1c was $8.6 \pm 1.9 \%$ and capillary blood glucose was measured $3.2 \pm 1.2$ times per day. Grade averages showed no correlation with HbA1c, diabetes duration, hypothyroidism, mental health issues, neither with hypoglycemia or ketoacidosis records. However, primary education Ch-T1D showed lower grades than Ch-GP $5.6 \pm 0.7$ and $6.0 \pm 0.2(\mathrm{p}=0,0002)$. School grades correlated with the number of capillary blood glucose readings per day, Pearson correlation coefficient (r) $0.25,0.41,0.52$ and 0.58 with general grade point average, math, language, and history average respectively $(\mathrm{p}<0.05)$. School non-pass rate was $6.1 \%$ in $\mathrm{Ch}-\mathrm{T} 1 \mathrm{D}$ and $4.8 \%$ in Ch-GP $(\mathrm{p}=0.65)$ and school dropout rate was $10.5 \%$ in Ch-T1D and $7.7 \%$ in Ch-GP $(\mathrm{p}=0.47)$. Conclusion: Ch-T1D attending primary school showed lower school grades than Ch-GP, and patients who more frequently checked capillary blood glucose showed better school grades. T1D may have a deleterious impact on school performance.
\end{abstract}

Keywords:

Type 1 diabetes, cognitive function, hyperglycemia, academic achievement 


\section{Introduction}

The prevalence and incidence of type 1 diabetes (T1D) in children and adolescents have increased worldwide $^{1}$. In Chile, the incidence of T1D in children under age 15 shows an increase of 5.4 to 8.3 per 100,000 inhabitants/year between years 2001 to $2004^{2}$, where the age range is under 4 years old and where the highest growth is observed ${ }^{3}$.

Despite the advances in Intensive insulin therapy, it is very difficult to reach an optimal metabolic control in the pediatric population ${ }^{4}$. Children and adolescents with T1D are completing their brain and cognitive development (mental processes which allow accomplishing a task) in the presence of chronic hyperglycemia, recurrent hypoglycemia and a glycemic variability out of physiological ranges. This is a cause of concern since, in adults, diabetes has been related to cognitive functions impairment, brain structure changes and apoptotic neuronal loss $s^{5-7}$.

Type 1 diabetes has been related to dysfunction of learning areas, memory, processing, attention, executive function and visual-motor integration ${ }^{8-11}$. A metaanalysis of Tonoli et al. ${ }^{12}$ reports that in children and adolescents with $\mathrm{T} 1 \mathrm{D}$, there is a modest impairment that affects the executive function areas, global intelligence (intelligence quotient) and motor nerve conduction velocity; the impairment is higher in adults than in children, mainly affecting the global intelligence (intelligence quotient), executive function, spatial memory, and motor nerve conduction velocity.

Nunley et al. proved that middle-aged adults, where the onset of T1D happened before the age of 18 , have a 5-times increased risk of cognitive impairment than the general population, mainly affecting psychomotor speed and visuospatial function. In addition, the greatest impairment was related to the poor metabolic control measured by glycosylated hemoglobin $(\mathrm{HbAlc})$ and a greater prevalence of cardiovascular compromise $^{13}$. Moreover, the long-term monitoring of young patients subgroup, aged between 13 and 19, which participated in the classic study DCCT ("Diabetes control and complication trial"), has proved that subjects with highest HbA1c during the 1990s, have developed a greatest psychomotor and mental efficiency areas impairment ${ }^{14-16}$.

The deleterious effect of T1D on some mental efficiency areas has been reported in limited groups of children with T1D against a control group. Hannonen et al. proved that a group of 51 children where the onset of T1D happened before the age of 5 when evaluated at an average age of 10 , showed impairments in the phonological process, reading, writing, and mathematics in relation to controls ${ }^{17}$. Northam et al. report an association between the frequency of severe hypoglyce- mias, the frequency of diabetic ketoacidosis, cumulative glycemic exposure and the duration of diabetes with cognitive compromise in patients with $\mathrm{T}_{1} \mathrm{D}^{18}$. Ryan et al. prove in an experimental study that adolescent-induced hypoglycemia negatively affects mental efficiency from 56 to $65 \mathrm{mg} / \mathrm{dl} \mathrm{glycemia}^{19}$. Gonder-Frederick et al. perform small mental calculation and simple selection standardized tests on children with T1D just before capillary blood glucose (CBG) measure on several times during their daily life, proving that mental calculation speed and reaction speed are significantly affected when blood glucose level is under $54 \mathrm{mg} / \mathrm{dl}$ and over $400 \mathrm{mg} / \mathrm{dl}$ with high interindividual variability $^{20}$, in such research, children were aware of their difficulties in hypoglycemia but they did not realize that their performance was affected by hyperglycemia. The deleterious effect of glycopenia is known, however, the mechanisms of neurological effects of hyperglycemia have been less studied. It has been postulated that hyperglycemia may affect the patency of the blood-brain barrier and in turn, it may affect the synthesis, availability, and reuptake of neurotransmitters such as serotonin $^{21}$.

It is reasonable to postulate that the glycemic variability may affect the capacity of paying attention in class and performance in school tests.

The impact of T1D in school performance has been explored with divergent results; this is probably due to different study methodologies. In 2016, Semencovich et al. study 61 individuals with T1D and 26 children as a control group using cognitive and academic tests, demonstrating that T1D patients performed poorly only in the area of verbal intelligence quotient and spelling ${ }^{22}$. MacCarthy et al. report that poor performance is related to a poor metabolic control in 244 children with T1D without control group ${ }^{23}$. In 2007, Dahlquist et al. study statistical data in Sweden and compares the performance of 5,159 subjects with T1D with a total school population of $1,330,968$ students, demonstrating lower performance in the diabetes group in sports, maths, English and language subjects ${ }^{24}$. Finally, in 2016, Cooper et al. report that a group of 666 children with T1D obtains similar qualifications of the general population in Australia in national standardized tests ${ }^{25}$.

We did not find studies that evaluate school performance in Chilean children with T1D. The aim of this study is to examine the relationship between academic qualifications and metabolic control in children with T1D and to compare their performance with the general population in the same region.

\section{Patients and Method}

A retrospective study was carried out to review the medical records of schoolchildren with T1D that were 
in control during 2015 at Pediatric Endocrinology Center of Dr. Leonardo Guzmán Hospital in Antofagasta.

39 out of 105 patients with diabetes were excluded for the following reasons: children under 7 years of age who had not entered the school system $(n=5)$; other types of diabetes (Type 2, MODY and Monogenic) $(\mathrm{n}=4)$; school dropout $(\mathrm{n}=9)$; high school graduates $(\mathrm{n}=7)$; immigrants who studied in another country during $2015(n=3)$; special education $(n=2)$ and children who have the onset during 2015 or who persisted on their honeymoon during $2015(\mathrm{n}=9)$. Finally, 66 patients were included in the study $(63 \%$ of evaluated medical records).

The percentage of school repeaters was calculated based on the 66 subjects included. The school dropout rate was calculated based on 86 school age subjects with T1D, without mental retardation, residents in Chile, who had not graduated from high school and were outside the school system by 2015 .

The data obtained were gender, age at July 31,2015 , age of T1D onset, duration of T1D (years), average glycosylated hemoglobin (HbAlc) during 2015, severe hypoglycemias history (needing help from a third party or with consciousness compromise), ketoacidosis after onset, presence of hypothyroidism and mental health problems whose diagnoses were based on the DSM-5 classification [26]. The number of CBG per day was obtained from the records of the computational discharges of the glucometer that is carried out in each control, calculating the average of all records from 2015 to January 2016.

The school performance data were obtained from the website www.ayudamineduc.cl, downloading the annual grades transcript of 2015 of each child, which specified both annual grade point average and the average of each subject. In Chile, school grades range from 1 to 7 , with 7 being the highest grade.

The HbAlc was measured in the same laboratory by turbidimetric inhibition immunoassay for whole hemolyzed blood. This assay is validated by NGSP (National Glycohemoglobin Standardization Program) with traceability to the reference method DCCT (Diabetes Control and Complications Trial) ${ }^{27-29}$.

Metabolic control measured by HbAlc, T1D progression time, T1D onset age and number of CBG per day were correlated with the grade point average of the patients, both annual and of each subject. Maths, language, and history were analyzed since such subjects exist at all levels and types of schools.

The grades of each child with T1D were compared with the grades of children in the general population of the same commune, who attended the same educational level, in the same type of school (municipal, subsidized private or private) during the same year. On the basis of this comparison, children with T1D were classified into three categories: with grade point average equal, lower or higher than the general population grade point average. The grade point average by level and commune of schoolchildren in the general population were provided by the Ministry of Education of our country (MINEDUC) with an enrollment of 105,032 students in the Second Region.

Statistical analysis was performed using STATA $12.0^{\circ}$ software, where proportion measures, central tendency and dispersion measures for the description of variables were applied. Regarding groups comparison, simple linear regression and Wilcoxon signedrank test (Mann y Whitney) were used, upon verification of breach of normality with Shapiro-Wilk test as the case may be. A value of $\mathrm{p}<0.05$ was considered statistically significant with $95 \%$ of reliability. The grade point average comparison was made by Student's t-test and the comparison of proportions was made by $\chi^{2}$.

The study was authorized by the management of the Hospital and the Ethics Committee of the University of Antofagasta, adhering to the Helsinki Declaration and regulations on the use of medical records.

\section{Results}

Table 1 shows the characteristics of the 66 patients with T1D, as entire group and divided by HbA1c, with no differences according to metabolic control. Most of the individuals were in pubertal stage and they were in primary education. All the patients with hypothyroidism were given levothyroxine, maintaining normal levels of the thyroid hormone. A $30 \%$ of the subjects had mental health problems and some patients had more than one disorder. The detected conditions corresponded to adjustment disorder $65 \%$, anxiety disorder $50 \%$, depression $20 \%$ and others $10 \%$.

Table 2 shows the grades by gender, the presence of hypothyroidism and mental health problems, with no differences between these categories except for the average grades in history subject which was lower for girls.

A $27 \%$ of the subjects had adequate metabolic control with HbAlc $\leq 7.5 \%{ }^{30}$. Table 3 shows grades of children with T1D divided by metabolic control and the grades of children of the general population in the Second Region. The grades of the entire group with T1D are similar to grades of the general population, however, children of primary education with T1D and from other communes, have lower grades than the general population. Table 4 shows grades of different subjects with no differences by metabolic control.

The linear regression analysis did not show correlation clinically significant between the grade point average and the duration of T1D $(r=0.0002, \mathrm{p}=0.99)$, 
Type 1 diabetes - R. Román R. et al

Table 1. Characteristics of patients with T1D as a total group and classified by HbA1c level

\begin{tabular}{|c|c|c|c|c|}
\hline & $\begin{array}{c}\text { Children with } \\
\text { T1D } \\
n=66\end{array}$ & $\begin{array}{l}\mathrm{HbA} 1 \mathrm{c} \\
<7.5 \% \\
n=18\end{array}$ & $\begin{array}{c}\mathrm{HbA} 1 \mathrm{c} \\
\geq 7.5 \% \\
n=48\end{array}$ & $\mathrm{p}$ \\
\hline Current age (years) & $13.4 \pm 2.9$ & $13.4 \pm 3.2$ & $13.2 \pm 2.6$ & 0.842 \\
\hline Age at debut (years) & $8.5 \pm 3.2$ & $9.2 \pm 3.0$ & $8.1 \pm 3.3$ & 0.188 \\
\hline T1D duration (years) & $5.3 \pm 3.2$ & $5.4 \pm 2.9$ & $4.6 \pm 3.5$ & 0.434 \\
\hline $\mathrm{HbA} 1 \mathrm{c}(\%)$ & $8.6 \pm 1.9$ & $6.7 \pm 0.5$ & $9.4 \pm 1.7^{*}$ & $<0.000$ \\
\hline Capillary blood glucose per day (n) & $3.2 \pm 1.2$ & $2.7 \pm 1.1$ & $3.2 \pm 1.2$ & 0.061 \\
\hline Hba1c < 7.5\% (\%) & 27 & 100 & $0 *$ & $<0.001$ \\
\hline Teen (\%) & 83 & 88 & 80 & 0.449 \\
\hline Males (\%) & 39 & 24 & 40 & 0.178 \\
\hline Hypothyroidism (\%) & 26 & 17 & 28 & 0.701 \\
\hline Mental health problems (\%) & 32 & 20 & 33 & 0.846 \\
\hline Primary education (\%) & 74 & 67 & 78 & 0.336 \\
\hline \multicolumn{5}{|l|}{ Type of school } \\
\hline Municipal (\%) & 61 & 66 & 61 & 0.837 \\
\hline Private subsidized (\%) & 35 & 28 & 35 & 0.699 \\
\hline Private non subsidized (\%) & 4 & 6 & 4 & 0.845 \\
\hline
\end{tabular}

$\mathrm{p}$ corresponds to statistical significance level when comparing the variable according to $\mathrm{HbA} 1 \mathrm{c}{ }^{*} \mathrm{p}<0.001$.

Table 2. Grades according to associated pathologies and gender in children with T1D $(n=66)$

\begin{tabular}{|c|c|c|c|c|c|c|c|c|c|}
\hline \multirow[t]{2}{*}{ Average Grades } & \multicolumn{3}{|c|}{ Hypothyroidism } & \multicolumn{3}{|c|}{ Mental Health Problems } & \multicolumn{3}{|c|}{ Gender } \\
\hline & $\begin{array}{c}\text { Yes } \\
(n=17)\end{array}$ & $\begin{array}{c}\text { No } \\
(n=49)\end{array}$ & $\mathrm{p}$ & $\begin{array}{c}\text { Yes } \\
(n=21)\end{array}$ & $\begin{array}{c}\text { No } \\
(n=45)\end{array}$ & $\mathrm{p}$ & $\begin{array}{c}\text { Girls } \\
(n=40)\end{array}$ & $\begin{array}{c}\text { Boys } \\
(n=26)\end{array}$ & $\mathrm{p}$ \\
\hline Annual & $5.5 \pm 0.6$ & $5.7 \pm 0.7$ & 0.297 & $5.5 \pm 0.7$ & $5.7 \pm 0.7$ & 0.284 & $5.6 \pm 0.7$ & $5.7 \pm 0.6$ & 0.551 \\
\hline Maths & $5.0 \pm 0.9$ & $5.2 \pm 1.1$ & 0.502 & $5.2 \pm 1.0$ & $5.2 \pm 1.1$ & 1.000 & $5.0 \pm 1.0$ & $5.3 \pm 1.1$ & 0.257 \\
\hline Language & $5.0 \pm 0.7$ & $5.3 \pm 0.8$ & 0.175 & $5.1 \pm 1.0$ & $5.3 \pm 0.8$ & 0.386 & $5.3 \pm 0.8$ & $5.2 \pm 0.7$ & 0.604 \\
\hline History & $5.0 \pm 0.7$ & $5.4 \pm 0.9$ & 0.101 & $5.1 \pm 0.9$ & $5.4 \pm 0.9$ & 0.212 & $5.1 \pm 0.9$ & $5.5 \pm 0.9 *$ & 0.041 \\
\hline
\end{tabular}

Table 3. Grades of children from the general population of the II Region and children with T1D as a total group classified by metabolic control

\begin{tabular}{|c|c|c|c|c|c|c|}
\hline & $\begin{array}{l}\text { II Region } \\
n=105032\end{array}$ & $\begin{array}{l}\text { Children T1D } \\
n=66\end{array}$ & $\mathrm{p}$ & $\begin{array}{l}\mathrm{HbA} 1 \mathrm{c}<7.5 \% \\
n=17\end{array}$ & $\begin{array}{l}\mathrm{HbA} 1 \mathrm{c} \geq 7.5 \% \\
n=48\end{array}$ & $\mathrm{p}$ \\
\hline Total group & $5.7 \pm 0.3$ & $5.6 \pm 0.7$ & 0.2501 & $5.6 \pm 0.8$ & $5.6 \pm 0.6$ & 1 \\
\hline \multicolumn{7}{|l|}{ By cycle } \\
\hline Primary Education & $6.0 \pm 0.2$ & $5.6 \pm 0.7 * *$ & 0.0002 & $5.6 \pm 0.8$ & $5.6 \pm 0.6$ & 1 \\
\hline Secondary Education & $5.5 \pm 0.3$ & $5.6 \pm 0.7$ & 0.4911 & $5.6 \pm 0.8$ & $5.4 \pm 0.6$ & 0.6241 \\
\hline \multicolumn{7}{|l|}{ By residence } \\
\hline Commune of Antofagasta & $5.7 \pm 0.3$ & $5.7 \pm 0.6$ & 1 & $5.7 \pm 0.7$ & $5.6 \pm 0.5$ & 0.6596 \\
\hline Others communes & $5.7 \pm 0.3$ & $5.4 \pm 0.8^{*}$ & 0.0365 & $5.2 \pm 1.0$ & $5.5 \pm 0.6$ & 0.5107 \\
\hline \multicolumn{7}{|l|}{ By type of school } \\
\hline Municipal & $5.6 \pm 0.3$ & $5.6 \pm 0.6$ & 1 & $5.5 \pm 0.8$ & $5.7 \pm 0.5$ & 0.4349 \\
\hline Private subsidized & $5.7 \pm 0.3$ & $5.4 \pm 0.7$ & 0.0519 & $5.6 \pm 0.8$ & $5.4 \pm 0.6$ & 0.6241 \\
\hline Private non subsidized & $6.0 \pm 0.2$ & $6.3 \pm 0.4$ & 0.3235 & 6.6 & $6.1 \pm 0.3$ & $(-)$ \\
\hline
\end{tabular}

II Region: indicates the average grade point of all schoolchildren in the general population of the Antofagasta Region. (-) cannot be calculated because there was only one child in a private non-subsidized school with $\mathrm{HbA} 1 \mathrm{c}<7.5 \%$. 
Table 4. Average grades according to HbA1c

\begin{tabular}{lccc}
\hline & $\begin{array}{c}\mathrm{HbA} 1 \mathrm{c}<7.5 \% \\
\mathrm{n}=18\end{array}$ & $\begin{array}{c}\mathrm{HbA} 1 \mathrm{c} \geq 7.5 \% \\
\mathrm{n}=46\end{array}$ & $\mathrm{p}$ \\
\hline HbA1c (\%) & $6.7 \pm 0.5$ & $9.4 \pm 1.7$ & 0.00 \\
$\begin{array}{l}\text { Annual grade point } \\
\text { average }\end{array}$ & $5.6 \pm 0.8$ & $5.6 \pm 0.6$ & 1 \\
Maths & $5.3 \pm 1.2$ & $5.1 \pm 1.0$ & 0.68 \\
Language & $5.0 \pm 0.9$ & $5.3 \pm 0.7$ & 0.31 \\
History & $5.2 \pm 1.1$ & $5.2 \pm 0.8$ & 0.93 \\
Technology & $6.0 \pm 0.8$ & $6.1 \pm 0.8$ & 0.71 \\
Arts & $6.2 \pm 0.7$ & $6.1 \pm 0.8$ & 0.63 \\
Physical education & $6.3 \pm 0.8$ & $6.3 \pm 0.7$ & 0.98 \\
Biology & $5.5 \pm 1.0$ & $5.2 \pm 0.8$ & 0.29 \\
English & $5.0 \pm 1.1$ & $5.4 \pm 0.9$ & 0.22 \\
\hline
\end{tabular}

Table 5. Characteristics of children with type 1 diabetes who have higher or lower grades than children of the general population of the same level, locality and type of school

\begin{tabular}{lccc}
\hline & \multicolumn{2}{c}{ Grades of children with T1D } & \\
& $\begin{array}{c}\text { < to General } \\
\text { Population } \\
n=34\end{array}$ & $\begin{array}{c}>\text { to General } \\
\text { Population }\end{array}$ & $p$ \\
& $n=27$ & \\
\hline Grades & $5.2 \pm 0.5$ & $6.2 \pm 0.3^{* *}$ & $<0.0000$ \\
HbA1c (\%) & $8.8 \pm 2.0$ & $8.1 \pm 1.2^{*}$ & 0.0201 \\
T1D duration (years) & $4.9 \pm 3.0$ & $5.3 \pm 3.4$ & 0.6728 \\
Age at debut (years) & $8.6 \pm 3.2$ & $8.3 \pm 3.3$ & 0.4501 \\
Blood glucose/day $(n)$ & $2.9 \pm 1.2$ & $3.4 \pm 1.2$ & 0.1515 \\
\hline
\end{tabular}

Note: There were five children who had equal grades to the general population who were excluded from this analysis. the HbAlc $(r=-0.003, \mathrm{p}=0.37)$, nor the age of diagnosis $(r=-0.05, \mathrm{p}=0.02)$, however, there was a correlation with the number of daily CBG as shown in figure 1. This correlation was significant for the grade point average, with a Pearson's coefficient $r(r=0.25$, $\mathrm{p}=0.0001)$, as well as for maths $(r=0.41, \mathrm{p}=0.013)$, language $(r=0.52, \mathrm{p}=0.025)$ and history $(r=0.58$, $\mathrm{p}=0.003)$.

By classifying patients with T1D by school performance in relation to the general population of the same sex, level, type of school and locality, $51 \%$ had a lower grade point average, $8 \%$ an equal grade point average and $41 \%$ a grade point average above the mean. Table 5 shows the HbAlc, duration of T1D, onset age and number of daily CBG in children with higher and lower performance than the general population. It is observed that children with lower grades than general population have worse metabolic control (higher HbAlc) with no differences in the other parameters.

Three patients had severe hypoglycemia during 2015; the history of severe hypoglycemia since the onset of T1D was found in 13 patients (ten children with one episode, one child with two episodes and three subjects with three episodes). There were no differences in the grades of those who had severe hypoglycemia $(5.8 \pm 0.6)$ and those who did not have such history $(5.6 \pm 0.7)(\mathrm{p}=0.564)$.

During 2015, six patients had an episode of ketoacidosis. The history of ketoacidosis after the onset was found in 32 patients, one episode in 22 subjects, two episodes in 7 patients and three episodes in a child. The grades were similar in children with and without a history of ketoacidosis $5.6 \pm 0.7$ and $5.7 \pm 0.7$ respectively $(\mathrm{p}=0.347)$.

Table 6 shows the number and percentage of children who were not promoted and dropout rates. A $10.5 \%$ of patients with T1D were out of the educational system and $6.1 \%$ of children with T1D were not promoted during the year 2015 without significant differences between children with T1D and the general population.

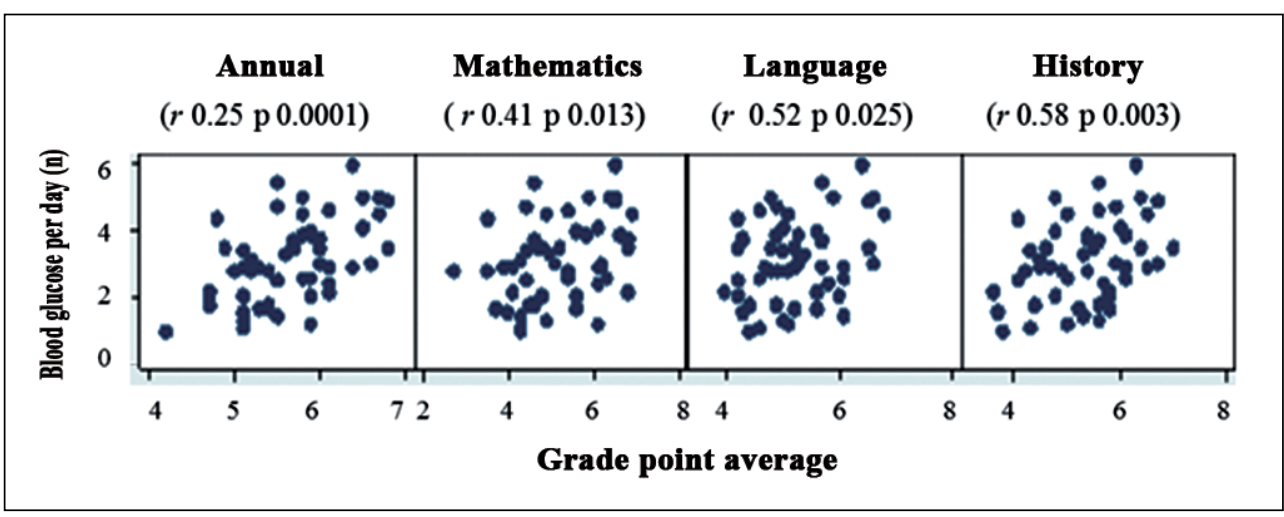

Figure 1. Study of correlation between the number of capillary blood glucose controls per day and the annual and Maths, Language and History grade point average in subjects with T1D. 
Table 6. Description of the number and percentage of children who were not promoted from grade or dropout from the school system in the general population of the II Region and in the group of children with T1D

\begin{tabular}{lccc}
\hline & General population schoolchildren & T1D Schoolchildren & $\mathrm{p}$ \\
\hline & $\mathrm{n}(\%)$ & $\mathrm{n}(\%)$ & \\
Not promoted in primary education & $2454(4.4)$ & $3(6.1)$ & 0.624 \\
Not promoted in secondary education & $2610(8.0)$ & $1(5.9)$ & 0.764 \\
Not promoted total group & $5064(4.8)$ & $4(6.1)$ & 0.651 \\
School dropout & $8087(7.7)$ & $9(10.5)$ & 0.336 \\
\hline
\end{tabular}

The general population of schoolchildren in the II Region includes 105,032 students.

\section{Discussion}

It has been shown that T1D cause deleterious cognitive effects in children and adolescents who have been followed prospectively at 2 and 6 years after onset $^{31}$. The most common cognitive deficits identified in patients with T1D are a slowing down in the speed of information processing ${ }^{32-35}$ and decreased psychomotor skills $s^{32,33,36}$. Other anomalies have been observed, such as motor nerve conduction velocity deficit ${ }^{34,37,38}$, vocabulary ${ }^{20,36,39}$, general intelligence ${ }^{40}$, visual image formation $^{35,40}$, attention ${ }^{35}$, somatosensory exam, motive power ${ }^{38}$, memory and finally, executive function ${ }^{36}$. Studies suggest, in turn, that both hypoglycemia and hyperglycemia affect the speed reaction and mathematical calculations, having a direct impact on the cognitive ability of children with T1D and poor metabolic control ${ }^{24}$. In children where the onset was before the age of 5 and with severe hypoglycemia history, it has been reported spatial intelligence and middle-term memory deficiencies, which suggest that developing brain could be susceptible to hypoglycemia ${ }^{41}$. In addition, T1D has been related to structural and functional changes in the brain ${ }^{7,41-43}$.

The evidence described above suggests that T1D could have consequences in neurodevelopment and in the cognitive process, both long and short term. However, T1D impact on school performance is still a matter of controversy ${ }^{11,22,24}$.

After the onset of T1D, children undergo a change in their lifestyle, they have frequent CBG, repeated medical check-ups, multiple daily insulin injections and changes in diet. Family overprotection and limitations in social activities are also frequent due to lack of autonomy in self-control and insulin therapy and fear of hypoglycemia. In addition, some patients and/ or their families react with rejection and denial of the disease. These factors can also create a detrimental environment for school performance independent of hyperglycemia ${ }^{25}$. In our series we observed that $30 \%$ of the children had mental health problems; however, this condition was not associated with a detriment in school grades.

In our research we did not find a correlation between school grades and the duration of T1D or HbAlc; furthermore, the grades of the entire group were similar to those of the general population of the Region. However, children with T1D in primary education showed lower grades than the general population. These results are inconsistent with Cooper et al. who report that in Australia, 666 children with T1D (ages 7-14) performed similarly to their peers on the National Assessment Program - Literacy and Numeracy (NAPLAN) tests ${ }^{25}$.

In our series, the school performance of children with adequate metabolic control versus with inadequate metabolic control was similar. Jacobson et al. also separate subjects by metabolic control but his observation was not focused on school performance. This study describes that individuals with $\mathrm{HbAlc}<7.4 \%$ have significantly better performance in motor nerve conduction velocity and psychomotor efficiency tests, compared to those subjects with an average HbAlc $>8.8 \%{ }^{44}$.

It was interesting to find a positive correlation between the number of daily CBG and grades as it has been established that the greater the number of daily CBG, the better the metabolic control ${ }^{45}$. It is possible that children who control their glycemia more frequently have better capillary glycemia levels during the study hours, enhancing their performance. On the other hand, we do not rule out that this association is only due to the fact that the most responsible children are more adherent to the treatment and self-control of their T1D, in the same way, that they are with their studies.

When comparing patients with T1D with higher and lower performance than the general population of the Region, we found that children with better performance have better metabolic control. These results are similar to the findings reported by McCarthy et al. ${ }^{23}$.

Our study has limitations such as the use of $\mathrm{HbAlc}$ 
as the only measure of metabolic control. HbA1c does not reflect the daily variations of glycemia, and the year average may have distortions, as we did not count on the quarterly measurement of this in all the patients. Likewise, no information regarding metabolic control from previous years was included.

Another limitation of this analysis is the limited number of patients and the control group. The general population is not limited to normal healthy children; general population includes both children with T1D and children with other chronic diseases that may adversely affect school performance.

The type of evaluation used to academically evaluate each patient could also distort our results. Many children with a number of chronic diseases are evaluated under the special education system, as part of a program for the inclusion and integration of children and youth with special educational needs, established in the General Education Act and Law 20,422 of current Chilean legislation ${ }^{46,47}$. This evaluation has a lower requirement in relation to their peers and could explain the lack of correlation between school performance and metabolic control in patients with T1D. Our methodology does not allow us to evaluate these privileges and/or discrimination, both positive and negative, in these patients.

It is interesting to note that our group of patients in control with T1D showed a dropout rate of $10.5 \%$, these patients were not included in the analysis of grades because they did not have academic records for 2015 . The Third Report Infancia Cuenta of the same year in the region of Antofagasta describes that in general population of the region there is a $7.7 \%$ dropout rate, with school dropout rate significantly higher in secondary education $(8.6 \%)$ versus primary education $(6.7 \%)^{47}$. The failure rate in 2015 of our group was $6.1 \%$; regional data for the general population report $4.8 \%$, where the national average is $4.6 \%$. Both dropout and failure seem to be higher in children with T1D in relation to the general population of the region, however, these differences did not reach statistical significance. Our methodology and the limited size of the study group do not allow us to make conclusive judgments regarding the real impact of T1D in this matter. It would be important to explore this history in a larger group of patients.

Our work did not make it possible to establish whether subjects who were out of the school system in 2015 have definitively dropped out of school or this is a transitory situation. In our experience, there are some families who are overtaken during the first months of the onset of T1D or during a subsequent crisis period and choose to take out the child from school to resume their studies the following year. Our findings suggest that it would be justified to implement a school sup- port program for children with T1D; both nursing to improve self-control during the school day, and pedagogical so that their school performance does not deteriorate.

\section{Conclusion}

Children with T1D in primary education showed lower grades than the general population. Patients who controlled their capillary glycemia less frequently had poorer school performance and subjects with lower grades than general population had poorer metabolic control. In this group of children who are assisted in the public health system in the Second Region of Chile, type 1 diabetes seems to have a deleterious impact on school performance.

\section{Ethical Responsibilities}

Human Beings and animals protection: Disclosure the authors state that the procedures were followed according to the Declaration of Helsinki and the World Medical Association regarding human experimentation developed for the medical community.

Data confidentiality: The authors state that they have followed the protocols of their Center and Local regulations on the publication of patient data.

Rights to privacy and informed consent: The authors have obtained the informed consent of the patients and/or subjects referred to in the article. This document is in the possession of the correspondence author.

\section{Financial Disclosure}

Authors state that no economic support has been associated with the present study.

\section{Conflicts of Interest}

Authors declare no conflict of interest regarding the present study.

\section{Acknowledgements}

We thank Mr. Cesar Velasco, Director of the Fundación de Diabetes Juvenil de Chile, and Mr. Rolando Álvarez Ojeda, Computer Engineer, in charge of Statistics and Management Department, Antofagasta Regional Ministerial Secretary, for their support to our research. 


\section{References}

1. Gale EA. The rise of childhood type 1 diabetes in the 20th century. Diabetes. 2002;51(12):3353-61.

2. Carrasco E, Angel B, Codner E, et al. [Type 1 diabetes mellitus incidence in Santiago, Chile. Analysis by counties in the period 2000-2004]. Rev Med Chile. 2006;134(10):1258-64.

3. Carrasco E, et al. Increasing incidence of type 1 diabetes in population from Santiago of Chile: trends in a period of 18 years (1986-2003). Diabetes Metab Res Rev. 2006;22(1):34-7.

4. Miller KM, Foster NC, Beck RW, et al. Current state of type 1 diabetes treatment in the U.S.: updated data from the T1D Exchange clinic registry. Diabetes Care. 2015;38(6):971-8.

5. Biessels GJ, Kerssen A, de Haan EH, Kappelle LJ. Cognitive dysfunction and diabetes: implications for primary care. Prim Care Diabetes. 2007;1(4):187-93.

6. Kodl CT, ER. Seaquist, Cognitive dysfunction and diabetes mellitus. Endocr Rev. 2008; 29(4):494-511.

7. Moheet A, Mangia S2, Seaquist ER. Impact of diabetes on cognitive function and brain structure. Ann N Y Acad Sci. 2015;1353:60-71.

8. Gaudieri PA1, Chen R, Greer TF, Holmes CS. Cognitive function in children with type 1 diabetes: a meta-analysis. Diabetes Care. 2008;31(9):1892-7.

9. Frier BM. Cognitive functioning in type 1 diabetes: the Diabetes Control and Complications Trial (DCCT) revisited. Diabetologia. 2011;54(2):233-6.

10. Ni J, Xin Y. [Cognitive function in children with type 1 diabetes]. Zhongguo Dang Dai Er Ke Za Zhi. 2012;14(8):571-4.

11. McCarthy AM, et al. Effects of diabetes on learning in children. Pediatrics, 2002;109(1):E9.

12. Tonoli C, Heyman E, Roelands B, et al. Type 1 diabetes-associated cognitive decline: a meta-analysis and update of the current literature. J Diabetes. 2014;6(6):499-513.

13. Nunley KA, Rosano C, Ryan CM, et al. Clinically Relevant Cognitive Impairment in Middle-Aged Adults With ChildhoodOnset Type 1 Diabetes. Diabetes Care. 2015;38(9):1768-76.

14. Lasker RD. The diabetes control and complications trial. Implications for policy and practice. N Engl J Med 1993;329(14):1035-6.

15. Musen G, Jacobson AM, Ryan CM, et al. Impact of diabetes and its treatment on cognitive function among adolescents who participated in the Diabetes Control and Complications Trial. Diabetes Care. 2008;31(10):1933-8.

16. Nathan DM, Genuth S, Lachin J, et al;
Diabetes Control and Complications Trial Research Group. The effect of intensive treatment of diabetes on the development and progression of longterm complications in insulin-dependent diabetes mellitus. N Engl J Med. 1993;329(14):977-86.

17. Hannonen R, Komulainen J, Eklund $\mathrm{K}$, Tolvanen A, Riikonen R, Ahonen T. Verbal and academic skills in children with early-onset type 1 diabetes. Dev Med Child Neurol. 2010;52(7):e143-7.

18. Northam EA, Anderson PJ, Jacobs R, Hughes M, Warne GL, Werther GA. Neuropsychological profiles of children with type 1 diabetes 6 years after disease onset. Diabetes Care. 2001;24(9):1541-6.

19. Ryan CM, Atchison J, Puczynski S, Puczynski M, Arslanian S, Becker D. Mild hypoglycemia associated with deterioration of mental efficiency in children with insulin-dependent diabetes mellitus. J Pediatr. 1990;117(1 Pt 1):32-8.

20. Gonder-Frederick LA, Zrebiec JF, Bauchowitz AU, et al. Cognitive function is disrupted by both hypo- and hyperglycemia in school-aged children with type 1 diabetes: a field study. Diabetes Care. 2009;32(6):1001-6.

21. McCall AL, Figlewicz DP. How does diabetes mellitus produce brain dysfunction? Diabetes Spectrum. 1997;10:25-32.

22. Semenkovich K, Patel PP, Pollock AB, et al. Academic abilities and glycaemic control in children and young people with Type 1 diabetes mellitus. Diabet Med. 2016;33(5):668-73.

23. McCarthy AM, Lindgren S, Mengeling MA, Tsalikian E, Engvall J. Factors associated with academic achievement in children with type 1 diabetes. Diabetes Care. 2003;26(1):112-7.

24. Dahlquist G, Kallen B. School performance in children with type 1 diabetes--a population-based register study. Diabetologia. 2007;50(5):957-64.

25. Cooper MN, McNamara KA, de Klerk NH, Davis EA, Jones TW. School performance in children with type 1 diabetes: a contemporary populationbased study. Pediatr Diabetes 2016;17(2):101-11

26. Association AP. Diagnostic and Statistical Manual of Mental Disorders FIFTH EDITION 2013.

27. Kilpatrick ES, Bloomgarden ZT, Zimmet PZ. International Expert Committee report on the role of the $\mathrm{A} 1 \mathrm{C}$ assay in the diagnosis of diabetes: response to the International Expert Committee. Diabetes Care. 2009;32(12):e159; author reply e160.

28. Sacks DB, Bruns DE, Goldstein DE, Maclaren NK, McDonald JM, Parrott $\mathrm{M}$. Guidelines and recommendations for laboratory analysis in the diagnosis and management of diabetes mellitus. Clin Chem. 2002;48(3):436-72.

29. Weykamp C, John WG, Mosca A, et al. The IFCC Reference Measurement System for HbAlc: a 6-year progress report. Clin Chem. 2008;54(2):240-8.

30. Rewers MJ, et al. ISPAD Clinical Practice Consensus Guidelines 2014. Assessment and monitoring of glycemic control in children and adolescents with diabetes. Pediatr Diabetes. 2014;15 Suppl20:102-14.

31. Brands AM, Kessels RP, Hoogma RP, et al. Cognitive performance, psychological well-being, and brain magnetic resonance imaging in older patients with type 1 diabetes. Diabetes. 2006;55(6):1800-6.

32. Ryan CM, Geckle MO, Orchard TJ, Cognitive efficiency declines over time in adults with Type 1 diabetes: effects of micro- and macrovascular complications. Diabetologia. 2003;46(7):940-8.

33. Ryan CM, Williams TM, Finegold DN, Orchard TJ. Cognitive dysfunction in adults with type 1 (insulin-dependent) diabetes mellitus of long duration: effects of recurrent hypoglycaemia and other chronic complications. Diabetologia. 1993;36(4):329-34.

34. Wessels AM, Rombouts SA, Remijnse $\mathrm{PL}$, et al. Cognitive performance in type 1 diabetes patients is associated with cerebral white matter volume. Diabetologia. 2007;50(8):1763-9.

35. Weinger K, Jacobson AM, Musen G, et al. The effects of type 1 diabetes on cerebral white matter. Diabetologia. 2008;51(3): 417-25.

36. Hershey T, Bhargava N, Sadler M, White NH, Craft S. Conventional versus intensive diabetes therapy in children with type 1 diabetes: effects on memory and motor speed. Diabetes Care. 1999;22(8):1318-24.

37. Ryan CM. Neurobehavioral complications of type I diabetes. Examination of possible risk factors. Diabetes Care, 1988;11(1):8693.

38. Hershey T, Craft S, Bhargava N, White $\mathrm{NH}$. Memory and insulin dependent diabetes mellitus (IDDM): effects of childhood onset and severe hypoglycemia. J Int Neuropsychol Soc. 1997;3(6):509-20.

39. Northam EA, Anderson PJ, Werther GA, Warne GL, Adler RG, Andrewes D. Neuropsychological complications of IDDM in children 2 years after disease onset. Diabetes Care. 1998;21(3):379-84.

40. Schoenle EJ, Schoenle D, Molinari L, Largo RH. Impaired intellectual development in children with Type I diabetes: association with $\mathrm{HbA}(1 \mathrm{c})$, age at diagnosis and sex. Diabetologia. 2002;45(1):108-14.

41. Hughes TM, Ryan CM, Aizenstein HJ, 
et al. Frontal gray matter atrophy in middle aged adults with type 1 diabetes is independent of cardiovascular risk factors and diabetes complications. J Diabetes Complications. 2013;27(6):558-64.

42. Musen G, Lyoo IK, Sparks CR, et al. Effects of type 1 diabetes on gray matter density as measured by voxel-based morphometry. Diabetes. 2006;55(2):32633.

43. Marzelli MJ, Mazaika PK, Barnea-Goraly $\mathrm{N}$, et al. Neuroanatomical correlates of dysglycemia in young children with type 1 diabetes. Diabetes. 2014;63(1):343-53.

44. Karter AJ, Ackerson LM, Darbinian JA, et al. Self-monitoring of blood glucose levels and glycemic control: the Northern California Kaiser Permanente Diabetes registry. Am J Med. 2001;111(1):1-9.

45. Miller KM, Beck RW, Bergenstal RM, et al. Evidence of a strong association between frequency of self-monitoring of blood glucose and hemoglobin Alc levels in T1D exchange clinic registry participants. Diabetes Care. 2013;36(7):2009-14.

46. http://www.educacionespecial.mineduc.cl. Ministerio de Educación de Chile. Unidad de Educación Especial.

47. Sepúlveda A, Santibáñez D, Díaz D, Contreras N, Valverde F, Cortés A. Observatorio Niñez y Adolescencia. Tercer Informe Infancia Cuenta en Chile www.observatorioniñez.cl/wp-content/ uploads/2015/11/Informe_Infancia_ Cuenta_Chile2015_Web2.pdf 2015. 